\title{
Mental (in)capacity or legal capacity? A human rights analysis of the proposed fusion of mental health and mental capacity law in Northern Ireland
}

\author{
EILIONÓIR FLYNN
}

National University of Ireland, Galway

\section{Introduction}

$\mathrm{T}$ The United Nations Convention on the Rights of Persons with Disabilities (CRPD) entered into force in 2007 and sets out in Article 12 that all human persons, regardless of their decision-making capabilities, should enjoy 'legal capacity' on an equal basis - that is, the right to be recognised as a person before the law, and the subsequent right to have one's decisions legally recognised. ${ }^{1}$ Simultaneously, the Bamford Review of Mental Health and Learning Disability in Northern Ireland published its final report that year, setting out principles for future legislation 'to provide equally for all circumstances in which an individual's autonomy might be compromised on health grounds' ${ }^{2}$ stating that such legislation should value the rights of persons with mental health needs or a learning disability, including 'their rights to full citizenship, equality of opportunity, and self determination'. 3

The continuities and discontinuities between the subsequent legislative proposal for the Mental Capacity (Health, Welfare and Finance) Bill (Northern Ireland) and the emerging consensus in international human rights law on the need for substitute decision-making regimes to be replaced by supported-decision-making ${ }^{4}$ have not been fully examined to date. In this paper, I seek to address the tensions between these two positions, in light of the Concluding Observations of the Committee on the Rights of Persons with Disabilities on Article 12 CRPD. Although mental health laws which permit involuntary detention and

1 See, for example, Tina Minkowitz, 'The United Nations Convention on the Rights of Persons with Disabilities and the Right to Be Free from Nonconsensual Psychiatric Interventions' (2006-2007) 34 Syracuse Journal of International Law and Commerce 405, 408; Amita Dhanda, 'Legal Capacity in the Disability Rights Convention: Stranglehold of the Past or Lodestar for the Future?' (2006-2007) 34 Syracuse Journal of International Law and Commerce 429; G Quinn with A Arstein-Kerslake, "Restoring the "Human" in "Human Rights": Personhood and Doctrinal Innovation in the UN Disability Convention' in C Gearty and C Douzinas (eds), The Cambridge Companion to Human Rights Law (Cambridge University Press 2012)

2 Bamford Review of Mental Health and Learning Disability (Northern Ireland), A Comprehensive Legislative Framework (Belfast 2007) 3.

3 Ibid.

4 See, for example, Consideration of Reports Submitted by States Parties under Article 35 of the Convention: Concluding Observations, Tunisia, Committee on the Rights of Persons with Disabilities (CRPD), 5th Session, 4, UN Doc CRPD/C/TUN/CO/1 (11-15 April 2011); Consideration of Reports Submitted by States Parties under Article 35 of the Convention: Concluding Observations, Spain, Committee on the Rights of Persons with Disabilities (CRPD), 6th Session, 5, UN Doc CRPD/C/ESP/CO/1 (19-23 September 2011). 
treatment of persons with psycho-social disabilities are also in need of reform according to Article 14 CRPD, I will focus my analysis in this paper on the need for reform in light of Article 12, since the proposed framework for Northern Ireland intends to apply the same legal standards to persons with mental health issues as to those with any other perceived deficits in decision-making ability. I will also highlight comparative law reform developments on legal capacity in other jurisdictions since the entry into force of the CRPD, with a particular focus on developments in the Republic of Ireland, given the requirement in the Good Friday/Belfast Agreement to ensure equivalence of protection for human rights on both sides of the border. ${ }^{5}$

Prior to the discussion of the law which follows, it is important to clarify at the outset the terminology used in this paper. The term 'mental capacity' refers to the decision-making skills of an individual, which naturally vary among individuals and may be different for a given individual depending on multiple factors (including environmental, social and other factors). By contrast, legal capacity is the recognition of an individual as both a holder of rights (with legal status or personality) as well as an actor in law (legal agency). ${ }^{6}$ In modern times, mental capacity has been used as a proxy for legal capacity in many instances meaning that, if a person does not meet a certain standard of decision-making ability, legal recognition of the validity of that individual's decision will be removed from the person and vested in a third party, who generally makes a decision based on the perceived 'best interests' of the person. This removal of legal capacity (generally based on a functional assessment of mental capacity) is referred to as substitute decision-making and can take many forms (including adult guardianship, and best interests decision-making under the Mental Capacity Act 2005 in England and Wales).

With the entry into force of the CRPD in 2007, the prevalence of the functional approach to mental capacity assessment, and the subsequent removal of legal capacity from individuals, began to be challenged from a human rights perspective. As will be discussed in further detail below, the CRPD introduced what Arstein-Kerslake and I refer to as the support model of legal capacity ${ }^{7}$ - based on the notion that legal capacity is a universal attribute and not a privilege to be granted only to individuals who have certain decisionmaking skills. This does not mean that we do not acknowledge that individuals have different levels of decision-making ability, or 'mental capacity', rather, we suggest that, instead of responding to deficits in decision-making by removing the legal authority to make binding decisions from individuals, the response most in keeping with the values and principles of the CRPD is to offer support to individuals in exercising their legal capacity. This support can take many forms, described further below, but one of the most commonly referred to is 'supported decision-making', which can be described as a formal decisionmaking agreement between an individual and one or more supporters, setting out areas of decision-making with which the person would like assistance, and which must be respected

5 C Ó Cinnéide, Equivalence in Promoting Equality: The Implications of the Multi-party Agreement for the Further Development of Equality Measures for Northern Ireland and Ireland (Equality Authority 2005) 1-64 <www.equality.ie/en/Publications/Policy-Publications/Equivalence-in-Promoting-Equality.html> accessed 11 October 2012.

6 International Disability Alliance, 'Legal Opinion on Article 12 of the CRPD' (21 June 2008) 1 $<$ www.internationaldisabilityalliance.org/representation/legal- capacity-working-group $>$ accessed 13 October 2011; Office of the United Nations High Commissioner of Human Rights, Legal Capacity (Background Conference Document 2005) 1, 13 <www.un.org/esa/socdev/enable/rights/ahc6documents.htm> accessed 13 October 2011.

7 E Flynn and A Arstein-Kerslake, 'Legislating Personhood: Realising the Right to Support in Exercising Legal Capacity' (2013) 9(4) International Journal of Law in Context (forthcoming). 
by third parties. Having clarified the terms to be used in the rest of the discussion, I will now turn to the current law in Northern Ireland and proposals for reform.

\section{Mental capacity and mental health: current law in Northern Ireland}

The main legislative provision governing mental health in Northern Ireland is the Mental Health (Northern Ireland) Order 1986. This order provides for the involuntary detention and treatment of persons with 'mental disorders'. 'Mental disorder' is defined in the Order as 'mental illness, mental handicap and any other disorder or disability of mind'. ${ }^{8}$ Therefore, the Order applies to persons with mental health needs (in the language of the Bamford Review) or psycho-social disabilities, and people with learning, or intellectual disabilities. The Order specifically excludes the following individuals from its scope: those with 'personality disorder, promiscuity or other immoral conduct, sexual deviancy or dependence on alcohol or drugs'?

The Order goes on to set out criteria for assessment (as to whether or not an individual should be detained and treated), involuntary detention and treatment in hospital, discharge, and procedural safeguards for detention and treatment - including recourse to the Mental Health Review Tribunal. In brief, an application for assessment can be made by an approved social worker or the person's nearest relative, and detention for the purposes of treatment can be authorised by a medical practitioner who certifies that the person has a mental illness or severe mental impairment which warrants detention, that failure to detain the patient would create a substantial likelihood of serious physical harm to himself or to other persons, and that no less restrictive alternatives to detention are available. ${ }^{10}$

The Order also provides for guardianship for persons with mental disorders, which is framed as a protective measure which is less restrictive than involuntary hospitalisation or imprisonment. Two types of guardianship are permitted under the Order - guardianship in s II provides for a patient over 16 (a person either with a mental disorder or 'appearing to be suffering from mental disorder') to be received into guardianship, where the disorder is of 'a nature or degree which warrants his reception into guardianship' and 'it is necessary in the interests of the welfare of the patient that he should be so received'. Under s III, courts can make a Guardianship Order in respect of persons with mental disorder who are convicted in criminal proceedings, as an alternative to imprisonment, and the guardian in these cases has the same powers as a guardian under s II.

Guardians have powers to require a person to reside at a particular place, to attend particular places at certain times for the purpose of medical treatment, occupation, education or training, and to provide access to the patient at any place where the patient is residing to any medical practitioner, approved social worker or other person. ${ }^{11}$ These powers seem to be far-ranging, and there is little oversight of how they are exercised, and virtually no ability on behalf of individuals subject to guardianship to challenge the appointment of a guardian, or contest the need for guardianship in a court process. Guardians are initially appointed under the order for a period of six months, and orders can be renewed for one-year periods thereafter. ${ }^{12}$

The Code of Practice for the Mental Health Order describes the purpose of guardianship as follows: 'to ensure the welfare (rather than the medical treatment) of a

8 S 3(1), Mental Health (Northern Ireland) Order 1986.

9 Ibid s 3(2).

10 Ibid s 12(1).

11 Ibid s 22(1)(a).

12 Ibid ss 22(3) and 23(1). 
patient in a community setting where this cannot be achieved without the use of some or all of the powers vested by guardianship'. 13 The Code also states that 'arrangements for giving effect to guardianship should not be unnecessarily complicated'14 and that guardianship should be used 'in a positive and flexible manner'. ${ }^{15}$ Further, it states 'if none of the powers given by guardianship are considered necessary for achieving the patient's welfare, then guardianship is inappropriate'. ${ }^{16}$ Guardians are also required by the Code to be willing to 'advocate' for the patient to services needed to carry out the person's care plan. ${ }^{17}$

In relation to the powers of guardians, the Code makes clear that, although the powers specified in the Order seem far-ranging, a guardian is not empowered to use force or compel an individual under guardianship to act against their will. For example, it states that:

the patient may be taken to the specified place if he willingly complies or offers no resistance. However, this power does not provide the legal authority to detain a patient physically in such a place, not does it authorize the removal of a patient against his will. If a patient is absent without leave from the specified place, he may be returned to it within 28 days by those authorized to do so 18

- namely, the police, or an approved social worker. Finally, the Code states that if a patiently consistently resists the exercise of the guardian's powers, it can be concluded that guardianship is not the most appropriate form of care for that person and guardianship should be discharged'. 19

It is clear that guardianship under the Mental Health Order allows for a form of substitute decision-making, albeit one that is intended, according to the Code, to be used sparingly. Although guardians appear to have powers to make decisions for those under their authority, guardians themselves cannot enforce these decisions. Although law enforcement and approved social workers can return an individual to a place specified by the guardian, there is no provision for guardians or others to override the individual's refusal of medical treatment, or to use force to gain access for professionals to an individual at their place of residence.

Other forms of substitute decision-making beyond guardianship in Northern Ireland are authorised under the common law - based on the judgments in $\mathrm{Re} F^{20}$ and $\operatorname{Re} C{ }^{21}$ The first judgment came in $R e F$ in 1990, which stated that doctors have the power, and in certain circumstances the duty, to treat patients who lack mental capacity in their best interests. A clear definition of mental capacity was not provided in the case. Subsequently, in $\operatorname{Re} C$, a person with schizophrenia refused an amputation of his gangrenous leg and the test of mental capacity the court applied was whether the individual could comprehend, take in and retain information, believe it, and weigh it up in order to make a decision. The court in $\operatorname{Re} C$ also emphasised that to have mental capacity an individual does not have to blindly accept medical evaluation and can have a level of self-assessment of any consequences. This definition is generally described as a functional assessment of mental capacity, and has subsequently been adapted and codified in the Mental Capacity Act 2005,

13 Department of Health and Social Services, Mental Health (Northern Ireland) Order 1986: Code of Practice (HMSO 1992) 27.

14 Ibid.

15 Ibid.

16 Ibid.

17 Ibid 28.

18 Ibid 33.

19 Ibid 24.

20 Re F v West Berkshire Health Authority [1990] 2 AC 1.

$21 \operatorname{Re} C$ [1994] All ER 118. 
but as this only applies to England and Wales, the need for reform in Northern Ireland had to be addressed separately.

\section{Beginning the reform process: the Bamford Review of Mental Health and Learning Disability}

The first concrete discussions about what such reforms should look like were commenced by the Bamford Review of Mental Health and Learning Disability, which began its work in 2002. The Bamford Review was commissioned in the wake of the Northern Ireland Act 1998 and the Human Rights Act 1998, which set the parameters for reform of the legal framework affecting persons with mental health and learning disabilities. The scope of the review was broad-ranging, as it examined the need to ensure equality and social inclusion for people with mental health and learning disabilities, as well as proposals for delivering better services. The review lasted five years and produced a number of reports on specific disabilities and services (e.g. Alzheimer's, autism-spectrum disorders, learning disability and mental health, forensic mental health services, alcohol and substance misuse, etc.) as well as some general overviews of equality legislation and a framework for mental health service delivery.

The two key reports for the purpose of this discussion are the 2006 report on Human Rights and Equality of Opportunity and the 2007 report on A Comprehensive Legislative Framework. The 2006 report contained a number of recommendations on mental capacity and human rights, stating that substituted decision-making could be contrary to human rights in certain circumstances, e.g. 'in relation to a person who is acknowledged to have capacity; in relation to a person who is deemed incapable, but who actually has capacity; and inappropriate substitute decision-making in relation to a person who does not have capacity'. ${ }^{22}$ Therefore, the 2006 report does not recognise that legal capacity is a universal right, not dependent on mental capacity, and similarly, does not acknowledge that substitute decision-making could de facto be considered a human rights violation. This follows the general trajectory of European Court of Human Rights jurisprudence on deprivation of legal capacity - which outlines concerns about the lack of procedural safeguards for individuals whose legal capacity is denied and is willing to criticise decisions made by substitute decision-makers which have led to bad outcomes for the individual (e.g. institutionalization in a restrictive and inappropriate setting), but has, to date, stopped short of finding that the denial of legal capacity in itself can constitute a violation of European Convention on Human Rights (ECHR) rights. ${ }^{23}$

Taking this as a starting point, the 2007 report goes on to set out key proposals for new legislation 'to provide equally for all circumstances in which an individual's autonomy might be compromised on health grounds'. ${ }^{24}$ In short, this seeks to apply the same legal framework to all persons perceived to lack mental capacity, whether the source of this lack of mental capacity is from a learning disability, mental health condition, or other cognitive disability, and whether the decision in question relates to an individual's medical treatment, personal or welfare decisions, or financial decision-making. The report recommends the adoption of a 'fusion' approach to legislative reform in this field.

22 Bamford Review of Mental Health and Learning Disability (Northern Ireland), Human Rights and Equal Opportunity (Belfast 2006) 25.

23 See, for example, Shtukaturov v Russia (App No 44009/05) [2008] ECHR 223; Stanev v Bulgaria (App No 36760/06) [2012] ECHR 46; DD v Lithuania (App No 13469/06) [2012] ECHR 254; X and Y v Croatia (App No 5193/09) [2011] ECHR 1835; Sykora v Caech Republic (App No 23419/07) [2012] ECHR 1960; Mibailovs v Latvia (App No 35939/10) [2013] ECHR 65; and Lashin v Russia (App No 33117/02) [2012] ECHR 63.

24 Bamford Review of Mental Health and Learning Disability (Northern Ireland), A Comprehensive Legislative Framework (Belfast 2007) 3. 
Essentially, this means that mental capacity regimes should not operate separately from mental health law which allows for involuntary detention and treatment on the basis of a 'mental disorder' and some criteria of risk (e.g. of harm to self and others). The idea is that, if the concept of mental capacity is taken seriously, and applied in the same way regardless of the individual's particular disability, then persons who are deemed to possess mental capacity (on the basis of a functional assessment of capacity) should be allowed to validly refuse medical treatment - including treatment for a mental health condition, even if there are risks involved. The result should be that involuntary treatment cannot be administered to a person who is found to have mental capacity to make a decision about consent to treatment, and that such treatment will only be given to persons who are found to lack mental capacity.

The fusion approach to mental health and mental capacity law adopted in the 2007 report is based in part on the work of Szmukler and Dawson, ${ }^{25}$ who published an article on this subject in 2006, and seem to have significantly influenced the findings of the Bamford Review. Szmukler and Dawson begin from the premise that both physical and mental illnesses should be treated consensually, and that any non-consensual treatment (of either a physical or mental health condition) is only justified if the individual lacks mental capacity. Therefore, they propose abandoning the criteria of risk to self or others - primarily used to justify involuntary treatment in the context of mental health. This was heralded by many, ${ }^{26}$ including the authors of the Bamford Review, as a progressive development which would respect the human rights of persons with mental health conditions on an equal basis with others, as it was thought to provide a less discriminatory basis for intervention than the mere presence of 'mental disorder' coupled with some level of risk.

However, this 'fusion' approach and the subsequent proposals for legislative reform, including those set out in the 2007 Bamford Report, were made in isolation from, and without full regard to, the emerging developments in international human rights law particularly the UN Convention on the Rights of Persons with Disabilities, as will be discussed further below. Therefore, scholars such as Bartlett ${ }^{27}$ have suggested that this kind of reform of 'mental capacity' should be approached with caution, as it may not yield the progressive, non-discriminatory results it promises. One of the problems identified by Bartlett is that the requirement in the assessment of functional capacity to understand and appreciate the nature and consequences of the decision is too flexible and has led to allegations that capacity means agreeing with the psychiatrist'. ${ }^{28}$ Further, he suggests that:

it is difficult to see that the incapacity can sensibly be separated from the mental disability, given that it is the mental disability that is the direct cause of the incapacity. Insofar as the use of the disability as a criterion is discriminatory, therefore, the use of incapacity as a detention criterion merely moves direct discrimination into indirect discrimination, and this is not really a significant advance. ${ }^{29}$

25 J Dawson and G Szmukler, 'Fusion of Mental Health and Incapacity Legislation' (2006) 188 British Journal of Psychiatry 504-09.

26 See, for example, N Rees, 'The Fusion Proposal: A Next Step' (paper delivered at the Rethinking Rights-Based Mental Health Laws Workshop, Monash University, Prato Campus, Italy, 22 May 2009); A Holland, 'The Model Law of Szmukler, Dawson and Daw: The Next Stage of a Long Campaign?’ (2010) 20 Journal of Mental Health Law 63.

27 See P Bartlett, 'A Mental Disorder of a Kind or Degree Warranting Confinement: Examining Justifications for Psychiatric Detention’ (2012) 16(6) International Journal of Human Rights 831-44.

28 Ibid 840.

29 Ibid 841. 
While the Bamford Review proposed that a fusion approach be adopted, it also set down some clear criteria for respecting the human rights of people with mental health and learning disabilities in the context of decision-making capacity. The 2007 report made explicit that legislative reform should be based on four key principles as follows:

Autonomy - respecting the person's capacity to decide and act on his own and his right not to be subject to restraint by others.

Justice - applying the law fairly and equally.

Benefit - promoting the health, welfare and safety of the person, while having regard to the safety of others.

Least Harm - acting in a way that minimises the likelihood of harm to the person.

Arguably, these principles could still provide a sound basis for legislative reform which more closely complies with the emerging human rights perspective on universal legal capacity from the CRPD. However, this would require a significant shift in focus from the comprehensive framework set out in the Bamford Review. Instead of assessing an individual's capacity to make a particular decision, using the functional approach, and providing for substitute decision-making where an individual is found to lack decisionmaking capacity, a CRPD-compliant approach would entail using the four principles to ground a support model of legal capacity, and ultimately abolishing involuntary treatment in mental health as well as other types of non-consensual medical treatment.

In response to the publication of the Bamford Review, the Northern Ireland Executive produced a consultation plan, Delivering the Bamford Vision, ${ }^{30}$ in 2008, and a follow-up action plan in 2009 based on the results of the consultation process. ${ }^{31}$ In the original consultation paper, the Executive proposed introducing separate but parallel legislation on mental health and mental capacity respectively and this position was reflected in the policy consultation document on a legislative framework for a Mental Health and Mental Capacity Bill published by the Department of Health in 2009.32

However, following consultation on Delivering the Bamford Vision and the Department of Health's consultation document on the proposed legislative framework, the Executive revised this position in a subsequent action plan, which stated that the Department of Health would lead the way in drafting a comprehensive legislative framework to address mental health and mental capacity in a single Bill. ${ }^{33}$ While the 2008 consultation document references work ongoing in the UK as a whole to ratify the CRPD - it does not connect obligations in the CRPD, particularly in Article 12, to the legislation being proposed, and the 2009 action plan did not reference the Convention at all.

Although the 2009 consultation paper on a legislative framework is clearly out of date since the agreement to publish a single Bill was reached, it does set out what a legislative framework would look like in Northern Ireland, on which more recent documents, including the Equality Impact Assessment of the proposed Bill, were based. For this reason, it is worth considering its key proposals here. With respect to capacity legislation, this

30 Department of Health, Social Services and Public Safety, Delivering the Bamford Vision: The Response of the Northern Ireland Executive to the Bamford Review of Mental Health and Learning Disability - Consultation Document (Belfast 2008).

31 Department of Health, Social Services and Public Safety, Delivering the Bamford Vision: The Response of the Northern Ireland Executive to the Bamford Review of Mental Health and Learning Disability - Action Plan 2009-2011 (Belfast 2009).

32 Department of Health, Social Services and Public Safety, Legislative Framework for Mental Capacity and Mental Health Legislation in Northern Ireland - A Policy Consultation Document (Belfast 2009).

33 Ibid 27. 
consultation document accepted that the four Bamford principles should be at the core of the legislative framework. While the consultation paper set out the need for mental capacity to be assessed, it does not provide much detail on who will assess capacity (except to say that where the decision involves consent to treatment, it should be assessed by a skilled professional). Similarly, although the document acknowledges that, where the person lacks mental capacity to make a decision, substitute decision-makers will come into play, no detail on who can be a substitute decision-maker (e.g. family member, professional) is provided.

The document also lists a number of powers and safeguards which will be included in the legislative framework, including: the opportunity to make advance decisions and lasting powers of attorney (LPAs) (where an individual has mental capacity at the time these are made); the appointment of deputies to make financial decisions on behalf of persons who lack mental capacity and do not have an advance decision or LPA; the creation of a new Office of Public Guardian; the statutory right for carers to have their views taken into consideration in substitute decision-making; advocacy services for those who lack capacity; a new offence of neglect or ill-treatment of persons who lack capacity; and deprivation of liberty safeguards for those who are placed in an institution without their consent and lack capacity to provide such consent. ${ }^{34}$

With regard to the mental health legislation, the consultation document proposed that assessment and treatment could continue to be carried out on a non-consensual basis if the person has a mental disorder, poses a significant threat to the health welfare and safety of themselves or others, and has impaired decision-making capacity in relation to treatment. Again, the failure to define impaired decision-making capacity leaves much uncertainty particularly as is it unclear whether a person must be actually found to lack capacity to make the decision as to assessment and treatment, or if any deficit at all in the individual's decision-making skills could lead to involuntary assessment and treatment. ${ }^{35}$

\section{Towards a single Bill on mental health and mental capacity in Northern Ireland}

The Equality Impact Assessment of the Mental Capacity (Health, Welfare and Finance) Bill published in 2010 provides more clarity and detail on the provisions of the proposed legislation, and does so based on the concept of a single Bill. The assessment of mental capacity was clarified as being a two-stage functional test. ${ }^{36}$ First, the individual had to have an impairment of, or disturbance in, the functioning of the mind or brain. Secondly, if, as a result of the impairment, the individual is unable to understand, retain, use and weigh information relating to the decision and communicate that decision to others, then the person will be found to lack mental capacity. ${ }^{37}$ This two-step test is an exact replica of the assessment of capacity provided for in the Mental Capacity Act 2005 England and Wales. ${ }^{38}$

The Equality Impact Assessment also proposed to apply the new legislative framework to persons aged 16 and over, ${ }^{39}$ although some exceptions were envisaged, e.g. in relation to contractual capacity (which is only recognised at 18) and the ability to establish an LPA (again, this would only be permitted at 18). ${ }^{40}$ It also proposed that, while, as envisaged in Bamford, the provisions of the new legislative framework should be equally applicable to

34 Department of Health, Social Services and Public Safety (n 32) 9-10.

35 Ibid 13-14.

36 Department of Health, Social Services and Public Safety, Mental Capacity (Health, Welfare and Finance) Bill Equality Impact Assessment (Belfast 2010).

37 Ibid 5.

38 Ss 2 and 3, Mental Capacity Act 2005.

39 Department of Health, Social Services and Public Safety (n 36) 5.

40 Ibid 7. 
persons in the criminal justice system, exceptions might be made for some individuals with a mental disorder in the criminal justice system who might possess mental capacity to make a decision regarding their medical treatment, but might be involuntarily treated nonetheless if they posed a substantial risk of serious harm to self and others. ${ }^{41}$

With regard to substitute decision-making where an individual is deemed to lack mental capacity, the Equality Impact Assessment proposed a four-pronged approach, based on the significance of the intervention to be made. The first, most common type of substitute decision is referred to as a 'routine' intervention and relates to the 'care, treatment and related expenditure which seek to meet the basic life and care needs of the person'. ${ }^{42} \mathrm{~A}$ formal assessment of mental capacity will not be conducted as a basis for this kind of intervention - rather, the substitute decision-maker (e.g. carer or health professional) may act in the best interests of the individual if she has a reasonable, objective, belief that the person lacks mental capacity to make the decision in question. Any action taken must also be the least restrictive of the person's freedom, and the individual must be given the opportunity to participate in the decision, with the substitute decision-maker having due regard to 'their past and present wishes, beliefs and values and regard for the views of others, including carers'. ${ }^{43}$ No automatic requirement to record substitute decisions made for routine interventions is envisaged in the Equality Impact Assessment.

The second category of substitute decision-making proposed relates to 'urgent interventions'. These are similar to routine interventions, but refer to situations where a decision needs to be made quickly in order to provide life-saving treatment. Due to the urgency of the situation, the Equality Impact Assessment states that it will not be appropriate for the person undertaking the intervention to undertake a full assessment of mental capacity'. 44 Therefore the substitute decision-maker is similarly empowered to act in the best interests of the individual if she has a reasonable belief that the individual lacks mental capacity. Substitute decision-makers must also take reasonable steps to establish if the individual has a lasting power of attorney and/or advance statement and take account of these in the decision to be made.

The third category of substitute decision-making set out in the Equality Impact Assessment refers to formal interventions in care, treatment, welfare or financial affairs 'which have significant consequences or are intrusive or restrictive'. 45 Due to the nature of these interventions, a formal assessment of mental capacity is proposed, based on the twostep test described above. The same safeguards apply as for less restrictive interventions and, in addition, a nominated person will be available to the person to ascertain her past and present wishes and ensure that these are communicated to the substitute decision-maker. If a nominated person is not identified or available, the individual is entitled to an advocate, who will fulfil the same role.

The final type of substitute decision-making relates to 'specifically authorised interventions' for care and treatment which have 'irreversible consequences, a high level of intrusiveness, complexity or risk, or are of a lengthy duration'. 46 These could include issues of organ donation, sterilisation, compulsory treatment for a 'mental disorder', deprivation of liberty, etc. In addition, the Equality Impact Assessment states that '[i]nterventions which

41 Department of Health, Social Services and Public Safety (n 36) 9.

42 Ibid 11.

43 Ibid.

44 Ibid 12.

45 Ibid.

46 Department of Health, Social Services and Public Safety (n 36) 12-13. 
would normally fall under formal interventions but where there is resistance, objection or dispute, will also be dealt with under this level'. ${ }^{47}$ Similar to formal interventions, these will require a formal assessment of mental capacity and written evidence supporting the intervention. The same safeguards as for formal interventions will be available to the individual, including a nominated person and/or advocate. The Equality Impact Assessment suggests that specific authorization for these interventions could be provided by a structure based on the existing Health and Social Care Trusts in Northern Ireland, overseen by the Regulation and Quality Improvement Authority. Authorisation for particularly serious interventions (involving life-saving treatment) may need to be provided for separately by the High Court.

There are a number of concerns with the proposed framework from a human rights perspective. Firstly, almost anyone the person interacts with can act as a substitute decisionmaker, with very little oversight and procedural safeguards for the individual, including limited rights of appeal. No explicit mention is made in the Equality Impact Assessment of how a person subject to best-interests decision-making can challenge the validity of a bestinterests substitute decision, or whether the intervention has been correctly classified (as routine, urgent, formal, or specifically authorised).

If, as it appears in the proposal, the individual's only recourse is to the High Court, this will make redress inaccessible for most people affected by substitute decision-making. Similarly, no reference to the right to instruct a solicitor appears in the proposals and so it is unclear whether capacity to instruct will be assessed, and by whom, or if solicitors can refuse the instructions of a client whom they believe lacks mental capacity. Northern Ireland has an Official Solicitor who 'provides legal representation for persons under a disability; this includes both minors (children under 18 years) and adults suffering from a mental disability (known as patients)'. ${ }^{48}$ The ability to challenge a decision of the Official Solicitor (who can, for example, consent to treatment on behalf of 'patients') is not addressed in the Equality Impact Assessment - neither does it provide guidance on when the Official Solicitor should be appointed to individuals under the proposed new legislative framework.

The procedural, due process safeguards for individuals under substitute decisionmaking and for those who are deprived of their liberty by an intervention under the new legislative framework are also problematic. While the Equality Impact Assessment references the need to provide safeguards for those deprived of their liberty who may not have consented to placement in a residential setting (based on HL $v U K$ ), ${ }^{49}$ it does not provide further detail on how such safeguards will be secured and, therefore, it appears that such deprivations of liberty would simply be authorised by a best-interests substitute decision. Specific deprivation of liberty safeguards do exist in the Mental Capacity Act 2005 (England and Wales) on which much of the Northern Ireland legislative framework is based - but these have been criticised for their piecemeal application ${ }^{50}$ and concerns about effective monitoring of the safeguards have been repeatedly raised. ${ }^{51}$

47 Department of Health, Social Services and Public Safety (n 36) 13.

48 Northern Ireland Courts and Tribunals Service, Royal Courts of Justice Customer Information: Official Solicitors Office $<$ www.courtsni.gov.uk/en-gb/aboutus/rcj/pages/royal\%20courts $\% 20$ of $\% 20 j$ ustice $\% 20$ customer $\%$ 20information.aspx\#Solicitors> accessed 7 May 2013.

49 App No 45508/99 [2004] ECHR 471.

50 See R Hargreaves, Deprivation of Liberty Safeguards: An Initial Review of Implementation (Mental Health Alliance 2010).

51 See L Series, Deprivation of Liberty Safeguards: A Haphazard Affair, Social Care Network, Guardian Professional <www.guardian.co.uk/social-care-network/2012/apr/02/deprivation-liberty-safeguards-improvements? $\mathrm{CMP}=$ twt_gu $>$ accessed 7 May 2013. 
In short, the Equality Impact Assessment entirely envisages the establishment of a substitute decision-making system, based on a medical model of disability and a functional assessment of mental capacity. The supports envisaged in the Bill to support individuals in the exercise of legal capacity - advance statements, LPAs, the availability of advocacy and the role of the nominated person - are relatively weak. For example, advance statements are not legally binding, and must only be 'had regard to' not followed, even where the individual is deemed to possess mental capacity, and LPAs only take effect once an individual has 'lost' mental capacity and cannot be revoked or amended once they have come into effect. The supports envisaged in the legislative framework exist in parallel with substitute decision-making and do not intend to replace it. Finally, while the proposed legislative framework purports to abolish involuntary detention and treatment permitted under the current Mental Health Order 1986 it does not in fact achieve this, as it envisages that persons with mental disorders in the criminal justice system and children may still be detained and treated against their will, regardless of any assessment which demonstrates that the individual has mental capacity for the decision in question.

\section{Consultation on legislative proposals and key concerns emerging}

In December 2010, the Department of Health subsequently published a synthesis report of the submissions it received during the consultation process on the Equality Impact Assessment. In this document, the department reaffirmed that the single Bill approach would be based on the four Bamford principles of autonomy, justice, benefit and least harm, stating that 'the Autonomy principle is the foundation on which the legislation will be based'. ${ }^{2}$ The document concluded that there was broad support for the department's proposal to legislate for a single Bill in this area, notwithstanding the complexity of the issues involved. Further detail was requested by many respondents in a number of areas including compulsory mental health treatment in the community, the application of the legislation in the criminal justice system, and the inclusion of persons with learning disabilities with 'abnormally aggressive or seriously irresponsible conduct' within the definition of mental disorder. ${ }^{53}$

One of the key findings of this document was the concern expressed by some respondents that, in terms of the legislative principles, there appeared to be a drift away from the 'Benefit' principle to one which emphasised 'Best Interests', which most felt was too paternalist in its focus. ${ }^{54}$ Other key recommendations from respondents included the need for independent advocacy to be provided for all levels of intervention under the Act ${ }^{55}$ (not just the more restrictive or intensive interventions) and the need for more due process protections and the ability to challenge both assessments of mental capacity and the decisions made under the various levels of intervention provided. ${ }^{56}$

Another key issue raised by submissions to the consultation paper was the treatment of children under the proposed legislative framework. Concerns were raised about the general exclusion of children under 16 from the Department's proposals, the failure to allow young people aged 16 and 17 to make lasting powers of attorney, and the exclusion of 16 and 17-

52 Department of Health, Social Services and Public Safety, Mental Capacity (Health, Welfare and Finance) Bill Equality Impact Assessment - Analysis of Responses (Belfast 2010) 3.

53 Ibid 6.

54 Ibid 8.

55 Ibid 10.

56 Ibid 9. 
year-olds from the deprivation of liberty safeguards to be adopted in the new legislation. ${ }^{57}$ Some submissions also requested a different kind of presumption of capacity for children - possibly adopting the 'mature minor' test as set out in Gillick $v$ West Norfolk. ${ }^{58}$ Consequently, it was recommended that the Children (NI) Order 1995 would have to be reviewed to bring it in line with the new legislative framework. ${ }^{59}$

The most recent consultation on the legislative proposals centred on the issue of extending the scope of the single Bill to the criminal justice system. A report on the responses to the consultation was published by the Department of Justice in January 2013. This report stated that many aspects of the criminal justice system in Northern Ireland already adopted a mental capacity approach - taking issues of decision-making capacity into account in determining the appropriate course of action, and welcomed the codification of this approach in the new Bill. The following issues were some of the key questions on which consultations were being sought:

The issues which then arose for the justice system ranged across day-to-day delivery of services within the justice system - how a police officer for example might apply the capacity approach in his/her daily routines; what constitutes best interests for the individual where a crime has been committed and a judge is choosing a sentence; or where a person is in a stressful custodial environment, how will that influence decisions? Protection of the individual and others is a heightened factor in the justice system. What role might 'third parties' play in a system well versed with formal legal representation? 60

In general, the findings of this consultation do not significantly depart from previous reports on the scope of the Bill - with the recommendation that most of the existing powers under the Mental Health Order in relation to criminal justice provisions should be retained. ${ }^{61}$ While the report acknowledged that the courts would maintain their independence in terms of sentencing, it recommended that the defendant's mental capacity be taken into account in this process. ${ }^{62}$ The report also recommended the retention of the police powers to remove a person suspected of suffering from a mental disorder to a place of safety, but also suggested that the places to which a person could be removed should be expanded beyond police stations, and that more community-based options should be available, including greater diversion opportunities for defendants with mental health problems. ${ }^{63}$

\section{Critical analysis of the proposed legislation from a human rights standpoint: the CRPD}

To date, there has been relatively little discussion about the need for the proposed legislative framework in Northern Ireland to comply with international human rights norms on legal capacity established in the CRPD. This is despite the ratification of the Convention and its Optional Protocol by the UK in 2009. The UK did not ultimately enter a declaration or reservation in relation to Article 12 on legal capacity, although it did consider a reservation

57 Department of Health (n 52) 6.

58 Gillick $v$ West Norfolk \& Wisbeck. Area Health Authority [1986] AC 112.

59 Department of Health, Social Services and Public Safety (n 52) 7.

60 Department of Justice, Consultation on Proposals to Extend Mental Capacity Legislation to the Criminal Justice System in Northern Ireland (Belfast 2013) 10 (emphasis in original).

61 Ibid 3.

62 Ibid 4

63 Ibid. 
on Article 12(4) ${ }^{64}$ and did enter declarations and reservations in respect of other issues, such as employment and education.

For clarity, it is worth setting out the key elements of Article 12 here, before examining the commentary to date on Northern Ireland's compliance with these provisions of the Convention. Article 12 states as follows:

1 States Parties reaffirm that persons with disabilities have the right to recognition everywhere as persons before the law.

2 States Parties shall recognize that persons with disabilities enjoy legal capacity on an equal basis with others in all aspects of life.

3 States Parties shall take appropriate measures to provide access by persons with disabilities to the support they may require in exercising their legal capacity.

4 States Parties shall ensure that all measures that relate to the exercise of legal capacity provide for appropriate and effective safeguards to prevent abuse in accordance with international human rights law. Such safeguards shall ensure that measures relating to the exercise of legal capacity respect the rights, will and preferences of the person, are free of conflict of interest and undue influence, are proportional and tailored to the person's circumstances, apply for the shortest time possible and are subject to regular review by a competent, independent and impartial authority or judicial body. The safeguards shall be proportional to the degree to which such measures affect the person's rights and interests.

5. Subject to the provisions of this article, States Parties shall take all appropriate and effective measures to ensure the equal right of persons with disabilities to own or inherit property, to control their own financial affairs and to have equal access to bank loans, mortgages and other forms of financial credit, and shall ensure that persons with disabilities are not arbitrarily deprived of their property.

The first paragraph reaffirms the status of persons with disabilities as persons before the law, i.e. as individuals possessing legal personality, with legal status and agency. This is confirmed by para 2, which extends the right to enjoy legal capacity on an equal basis with others to all aspects of life. Some might argue that functional assessments of mental capacity (which result in the removal of an individual's legal capacity in respect of a particular decision) conform with Article 12(2), since all adults, regardless of whether or not they have a disability, could, in theory, be subject to a functional assessment of their mental capacity, and have their legal capacity removed for a particular decision if they fail to meet a certain standard of decision-making ability.

However, since most functional assessments of capacity, including the one proposed in Northern Ireland's new legislative framework, require as a first step that the individual have an 'impairment in the functioning of the mind or brain', this means that, in reality, the functional assessment of mental capacity is disproportionately applied to people with disabilities, especially those with cognitive disabilities including psycho-social disability, intellectual disability, and people with dementia. Therefore, as Arstein-Kerslake and I have argued elsewhere, ${ }^{65}$ when Article 12 is read in conjunction with Article 5 (Equality and

64 In the early stages of the ratification process, the UK government did consider entering a reservation to Art 12(4), on the basis that no review process was in place for appointees who collected payments from the Department of Work and Pensions on behalf of persons with disabilities who 'lack physical or mental capacity'. This reservation was subsequently dropped and not included in the final reservations and declarations submitted to the UN. See Department of Work and Pensions, Explanatory Memoradum on the Ratification of the UN Convention on the Rights of Persons with Disabilities (London, 3 March 2009).

65 E Flynn and A Arstein-Kerslake, 'The Support Model of Legal Capacity: Fact, Fiction, or Fantasy?' (2013) 30(4) Berkeley Journal of International Law (forthcoming). 
Non-Discrimination), the use of functional assessment of mental capacity to justify substitute decision-making is discriminatory (in both purpose and effect) towards persons with disabilities. This interpretation is now reflected in the Committee's Draft General Comment on Article 12.66

Paragraph 3 contains one of the more novel additions to Article 12 - a state obligation to provide the supports required to exercise legal capacity. As discussed in the Introduction above, this support can take many forms, including, but not limited to, formal agreements with supporters who assist in certain areas of decision-making. Paragraph 4 addresses the safeguards required for all measures regarding the exercise of legal capacity. Some argue that this provision allows for some limited forms of guardianship to remain if the appropriate safeguards are in place, ${ }^{67}$ however, the Committee on the Rights of Persons with Disabilities has not accepted this argument from any of the countries it has examined to date - even those countries which have interpretative declarations on Article 12, setting out interpretations that Article 12 permits some limited forms of substituted decision-making. ${ }^{68}$

The key phrase in Article 12(4), and one which has been used repeatedly by the Committee on the Rights of Persons with Disabilities in its concluding observations on the countries examined to date, is that safeguards should be designed to respect the 'rights, will and preferences' of the person. The term 'best interests' does not appear in para 4, or in Article 12 at all. Therefore, I would argue that safeguards which are paternalistic in nature, or which envisage the use of substitute decision-making are not permitted under Article 12. Finally, para 5 refers specifically to the need to respect legal capacity with regard to financial affairs and property - an issue which was subject to extensive debates during the negotiation of the CRPD.

The Committee has repeatedly called for the abolition of regimes of substitute decisionmaking and their replacement with systems of supported decision-making in each of the seven concluding observations it has issued to date. ${ }^{69}$ In each of its Concluding Observations on these countries, the Committee expressed concern 'that no measures have been undertaken to replace substitute decision-making by supported decision-making in the exercise of legal capacity'. ${ }^{70}$ With respect to all countries, the Committee recommended that the states 'review the laws allowing for guardianship and trusteeship, and take action to develop laws and policies to replace regimes of substitute decision-making by supported decision-making, which respects the person's autonomy, will and preferences. ${ }^{71}$ This

66 Committee on the Rights of Persons with Disabilities (CRPD), Draft General Comment on Article 12: Advance Unedited Version, 10th Session (2-13 September 2013), paras 9, 21 and 28.

67 See Canada's Reservation to the CRPD, Art 12 (11 March 2010). However, the United Nations Committee on the Rights of Persons with Disabilities (CRPD) has recently noted in several of its concluding observations that steps should be taken to replace substituted decision-making with supported decision-making: Committee on the Rights of Persons with Disabilities (CRPD) Tunisia (n 4); Committee on the Rights of Persons with Disabilities (CRPD) Spain (n 4).

68 See, for example, Consideration of Reports Submitted by States Parties under Article 35 of the Convention: Concluding Observations, Australia, Committee on the Rights of Persons with Disabilities (CRPD), 10th Session, UN Doc CRPD/C/AUS/CO/1 (2-13 September 2013).

69 See, for example, Committee on the Rights of Persons with Disabilities (CRPD) Tunisia (n 4); Committee on the Rights of Persons with Disabilities (CRPD) Spain (n 4).

70 Consideration of Reports Submitted by States Parties under Article 35 of the Convention: Concluding Observations of the Committee on the Rights of Persons with Disabilities, Committee on the Rights of Persons with Disabilities, 5th session, 4 (11-15 April 2011) <www.ohchr.org/EN/HRBodies/CRPD/Pages/Session5.aspx> accessed 26 April 2013.

71 Consideration of Reports Submitted by States Parties under Article 35 of the Convention: Concluding Observations of the Committee on the Rights of Persons with Disabilities, Committee on the Rights of Persons with Disabilities, 6th session, 5 (19-23 September 2011) <www.ohchr.org/EN/HRBodies/CRPD/Pages/Session6.aspx> accessed 17 May 2013. 
approach demonstrates the Committee's acceptance of the need for a support model of legal capacity to be implemented in States Parties to the Convention; and following the publication of the Committee's Draft General Comment more guidance has been provided on the definitions of 'substitute decision-making regimes' and 'supported decision-making' respectively. Substitute decision-making is defined as follows:

a system where 1) legal capacity is removed from the individual, even if this is just in respect of a single decision, 2) a substituted decision-maker can be appointed by someone other than the individual, and 3) any decision made is bound by what is believed to be in the objective 'best interests' of the individual - as opposed to the individual's own will and preferences. ${ }^{72}$

By contrast, the Committee provides a broad interpretation of 'supported decision-making', as 'a cluster of various support options which give primacy to a person's will and preferences and respect human rights norms'. ${ }^{73}$ A non-exhaustive list of support options is provided in the draft General Comment, from relatively minor accommodations, such as accessible information, to more formal measures such as supported decision-making agreements nominating one or more supporters to assist the individual in making and communicating certain decisions to others. ${ }^{74}$ The Committee also clarifies that legal capacity is a universal attribute, ${ }^{75}$ and that it cannot be made contingent on the individual's level of mental capacity. ${ }^{76}$

Further to the Committee's interpretation, and building on the work of Bach and Kerzner, Arstein-Kerslake and I have suggested some additional components of the support model of legal capacity as enshrined in Article 12. We argue that it is crucial that supports for exercising legal capacity could be offered to the individual, but not imposed. ${ }^{77}$ In situations where the person's will and preferences remain unknown after significant efforts to discover these have been made, 'facilitated' decision-making ${ }^{78}$ could be available, where someone could be appointed to make a decision on behalf of another individual as a last resort. In all situations where support is provided, the most important safeguard, as has been emphasised by the Committee, is the need for decisions to reflect the rights, will and preferences of the individual receiving support. ${ }^{79}$ Having considered the possible implications and interpretations of Article 12, I will now turn to the UK position on legal capacity and its obligations under the CRPD.

In the UK's initial report to the Committee on the Rights of Persons with Disabilities, the section on Article 12 states that: 'The UK Government strongly supports the equal recognition of disabled people before the law, and their right to exercise legal capacity. ${ }^{80} \mathrm{It}$ is important to note also that the UK government position on treaty ratification is that it will only ratify once all necessary laws have been enacted to ensure conformity with the

72 Committee on the Rights of Persons with Disabilities (CRPD), Draft General Comment on Article 12 (n 66) para 23.

73 Ibid para 25 .

74 Ibid para 15.

75 Ibid para 8.

76 Ibid para 12.

77 Flynn and Arstein-Kerslake (n 65) 5.

78 The concept of facilitated decision-making was conceptualized by Michael Bach and Lana Kerzner in 'A New Paradigm for Protecting Autonomy and the Right to Legal Capacity' prepared for the Law Commission of Ontario (October 2010) <www.lco-cdo.org/disabilities/bach-kerzner.pdf> accessed 17 May 2013.

79 Committee on the Rights of Persons with Disabilities (CRPD), Draft General Comment on Article 12 (n 66) para 15.

80 Office for Disability Issues, UK Initial Report on the UN Convention on the Rights of Persons with Disabilities (London 2011) 17. 
Convention. ${ }^{81}$ However, the report also states that: 'There may be circumstances in which a disabled person needs support to exercise that capacity, or where they lack the mental capacity to make decisions for themselves, and decisions may then be made on their behalf. ${ }^{82}$ The highlighted portion of the second statement clearly indicates that the UK, including Northern Ireland, has taken the stance that substitute decision-making is permissible for persons with disabilities who are deemed to 'lack mental capacity' - usually according to the functional test as explained in the Introduction above.

This does not, however, accord with the Committee's own statements on substitute decision-making which will be discussed further below. There is only one reference to Northern Ireland in the Article 12 section of the UK report, which states that: 'In Northern Ireland, the Mental Health (NI) Order 1986 currently provides a framework for the Courts to manage and administer the finance, property and affairs of adults who lack capacity. ${ }^{93}$ No further discussion of the reforms related to Article 12 underway in Northern Ireland, including the proposal for a single Bill on mental health and mental capacity, and whether these reforms will comply with the CRPD, is made in the UK report.

The only shadow report published to date on the UK, written by the Deaf Ex-Mainstreamers Group, ${ }^{84}$ focuses on Article 24 (Inclusive Education) and does not address the issue of legal capacity. An expert paper on disability policy and programmes in Northern Ireland was commissioned by the Equality Commission and published in 2011.85 This paper covers all articles of the Convention, analysing the relevant policies and programmes in Northern Ireland and their compliance with the Convention, and combining this with insights from focus groups of disabled people. Although the section of this expert paper examining Article 12 is relatively brief, it does make some important points. With regard to Article 12(3), the paper states as follows:

Whilst the requirements of Article 12(3) may be seen as resource intensive, there is no reason to believe that the right to access the support needed to exercise one's legal capacity is a socio-economic right and thus is a progressively realisable obligation on States Parties as per CRPD Article 4(2). Recognition as a person before the law is an example of a classic civil and political right and it is of immediate effect. With respect to persons with disabilities, the obligation to take measures to ensure access to support under Article 12(3) is also of immediate effect. This means that Article 12(3) is not an obligation to provide access only through taking 'measures to the maximum of its available resources' (Article 4(2)). Article 12(3) support must also not be seen as a form of 'reasonable accommodation' which is subject to limitation in 'not imposing a disproportionate or undue burden' (Article 2). ${ }^{86}$

The paper also supports the position that distinctions in the enjoyment of legal capacity which are based on disability are discriminatory and contrary to the spirit and intention of the CRPD. Based on my argument above regarding the discriminatory nature of functional assessments of capacity (especially where these tests are premised on the existence of an

81 Foreign and Commonwealth Office, Treaties and MOUs: Guidance on Practice and Procedures (London 2012) 6.

82 Office for Disability Issues, UK Initial Report on the UN Convention on the Rights of Persons with Disabilities (London 2011) 17 , emphasis added.

83 Ibid 18 (bold in original).

84 Deaf Ex-Mainstreamers Group, Shadow Report to the UN Secretary General and the Committee on the Rights of Persons with Disabilities (London 2011).

85 C Harper, S McClenahan, B Byrne and H Russell, Disability Programmes and Policies: How Does Northern Ireland Measure Up? Monitoring Implementation (Public Policy and Programmes) of the United Nations Convention on the Rights of Persons with Disabilities (UNCRPD) in Northern Ireland (Equality Commission 2011).

86 Ibid 124. 
impairment in functioning of the mind or brain), this would seem to indicate that the current legislative framework on mental capacity being proposed in Northern Ireland should be revised. Finally, the results of the questionnaire distributed by the authors of the expert paper indicated that mental health and capacity was the fourth highest priority for change in light of the CRPD for non-disabled respondents and the sixth highest priority for change overall. ${ }^{87}$ The comments made by respondents on this issue focused on stigma, knowledge deficits and discrimination, but few identified what kind of reform they wished to see, which is perhaps unsurprising, given the complexity of this issue and the lack of campaigning from the disability movement or civil society as a whole in Northern Ireland on the need to move away from substitute decision-making. ${ }^{8} 8$

No statement regarding Northern Ireland's position on Article 12 and the proposed legislative reforms has been made by either the Equality Commission of Northern Ireland, or the Northern Ireland Human Rights Commission. However, the Independent Mechanism established under Article 33 of the CRPD to monitor the implementation of the Convention at domestic level (a task shared by the Human Rights and Equality Commissions in Northern Ireland) did provide advice to government on the scope of the proposed legislation in light of the CRPD, and its application to children in particular. ${ }^{89}$ While this report does not challenge the central assumption that functional assessments of mental capacity which result in the removal of legal capacity are contrary to Article 12, it does refer to the need for the legislation to focus more squarely on 'supported decision-making' rather than simply providing for different kinds of 'substitute decision-making' to occur:

There is a contrast between Article 12, which emphasises supported decision making and the Bill, which establishes a system of substitute decision making. Article 12 aims to facilitate decision making with the person, rather than for the person. In this context, the Bill must ensure that persons experiencing difficulties with decision making have access to the support necessary to make a decision themselves. ${ }^{90}$

This statement is one of the only examples of critique of the legislative proposals in Northern Ireland to date from the standpoint of Article 12. Some awareness-raising about the need to further reform the legislative proposals was conducted by Mencap, which organised a roundtable on legal capacity in conjunction with Inclusion Europe, Inclusion Ireland, the Law Centre of Northern Ireland and the Centre for Disability Law and Policy, National University of Ireland Galway, in November 2012. ${ }^{91}$ While officials from the Departments of Justice and Health attended the roundtable, the impression they gave was that the legislation was almost finalised and, subject to the consultation discussed above about the extension of the proposals to the criminal justice system, the legislative framework would remain as set out in the Equality Impact Assessment in 2010, with a functional assessment of mental capacity, and four different types of interventions allowing for substitute decisions to be made in the best interests of a person deemed to lack sufficient mental capacity.

Therefore, it seems that the approach to be taken in Northern Ireland will follow closely the legislation currently in force in England and Wales (Mental Capacity Act 2005) and

87 Harper et al (n 85) 127.

88 Ibid.

89 UN Convention on the Rights of Persons with Disabilities Independent Mechanism for Northern Ireland, Advice to Government on the Mental Capacity (Health, Welfare and Finance) Bill (Belfast 2012).

90 Ibid 3.

91 See Mencap Northern Ireland, ‘An Opportunity to Turn Rights into Reality' press release, 26 November 2012 <www.mencap.org.uk/news/article/opportunity-turn-rights-reality> accessed 27 May 2013. 
Scotland (Adults with Incapacity (Scotland) Act 2000). All three are premised on a functional assessment of mental capacity which leads to the subsequent removal of legal capacity in respect of a particular decision, and substitute decision-making which follows a best-interests approach. As discussed above, such systems have already been described by other scholars as potentially conflicting with the requirements of Article 12 CRPD. ${ }^{92}$ In addition, the paternalistic approach of the Court of Protection in England and Wales to the authorisation of best-interests decision-making and the lack of due process safeguards and access to justice for individuals subject to substitute decision-making in these systems has also been criticised. ${ }^{93}$

In the following section, I contrast this position with current developments in legal capacity legislation in the Republic of Ireland, with a view to advocating that a consistent approach be taken in both jurisdictions, in order to ensure equivalence of human rights protection on both sides of the border, in light of the Belfast/Good Friday Agreement.

\section{Legal capacity reform in Ireland: implementing the CRPD}

The Republic of Ireland has committed to reform its outdated substitute decision-making regime, known as the ward of court system, prior to ratifying the Convention. The current ward of court system in Ireland encapsulates a status-based approach to legal capacity, whereby a person of 'unsound mind' who is 'incapable of governing his person or property' is deprived of all legal rights in respect of decision-making. ${ }^{94}$ A Law Reform Commission Report published in $2006^{95}$ (prior to the adoption of the CRPD) recommended the introduction of a functional assessment of mental capacity, and the subsequent appointment of personal guardians if an individual was found to lack sufficient mental capacity for the relevant decision. However, since the entry into force of the Convention, discourse in the Republic about the possible scope and outlook of new capacity legislation has moved away from substitute decision-making towards a support model of legal capacity.

The present Minister for Justice, Alan Shatter, made the following statement in Parliament to the effect that Ireland would not ratify until the necessary legislative reforms were completed: 'Ireland does not become party to treaties until it is first in a position to comply with the obligations imposed by the treaty in question, including by amending domestic law as necessary. 96 When the present government came to power in 2011, its Programme for Government contained a commitment to introduce a 'Capacity Bill that is in line with the UN Convention on the Rights of Persons with Disabilities'. ${ }^{97}$

The parliamentary joint committee on Justice, Defence and Equality ('the Justice Committee') subsequently called for submissions in August 2011 from interested parties on the content of what was being referred to at the time as the Mental Capacity Bill. ${ }^{98}$ In response, a coalition of interested organisations and individuals, in the fields of intellectual

92 See P Fennell and U Khaliq, 'Conflicting or Complementary Obligations? The UN Disability Rights Convention, the European Convention on Human Rights and English Law' (2011) (6) European Human Rights Law Review 662-74; Bartlett (n 27).

93 See Series (n 51).

94 Lunacy Regulation Act 1871 (c 22/1871) (Ir).

95 Law Reform Commission, Report: Vulnerable Adults and the Law (Law Reform Commission 2006).

96 Dail Debates, 22 May 2012, Written Answers: National Disability Strategy <http://debates.oireachtas.ie/dail/ 2012/05/22/00318.asp> accessed 26 April 2013.

97 Department of An Taoiseach, Programme for Government 2011 (Government Publications 2011) 8 <www.taoiseach.gov.ie/eng/Publications/Publications_Archive/Publications_2011/Programme_for_Gover nment_2011.pdf $>$ accessed 26 April 2013.

98 Oireachtas Joint Committee on Justice, Defence and Equality, Mental Capacity Legislation: Invitation for Submissions (August 2011) <www.oireachtas.ie/parliament/mcl/> accessed 12 February 2013. 
disability, mental health, and older people, co-chaired by the Centre for Disability Law and Policy, National University of Ireland Galway, and Amnesty International Ireland's Mental Health Campaign, came together to discuss whether a joint approach to legal capacity reform could be developed across these interest groups.

The result was the publication of an agreed set of Essential Principles for Legal Capacity Reform in April 2012, setting out 10 key principles to be adhered to in legislation designed to comply with Article 12 CRPD. ${ }^{99}$ Key requirements in these principles included the need for support to fully replace substitute decision-making, the abolition of best interests as a criteria in decision-making and its replacement with an approach that respected the 'will and preferences of the person' and the state obligation to provide a range of support options to individuals who wish to use support in exercising their legal capacity. Many of the groups involved presented at oral hearings convened by the Justice Committee in February 2012.100 The Justice Committee also published a report based on the oral hearings, endorsing the support model of legal capacity and requiring a shift away from the best-interests model of substitute decision-making towards an approach which respects the will and preferences of the individual. ${ }^{101}$

To begin with, what is needed is a starting point whereby we accept that all persons have legal capacity and are capable of making decisions regarding what to do in all areas of life... It is essential that the new legislation ensures that persons with disabilities have access to supports which allow them to fully enjoy all human rights. We as a society must move away from paternalism and fully recognise the 'will and preferences' of the individual as required by Article 12(4) of the UN Convention on the Rights of Persons with Disabilities. ${ }^{102}$

The Legal Capacity Bill was suggested as a more appropriate title for this legislation as required by international human rights law. Legal capacity - the capacity to hold and exercise rights - should be distinguished from mental capacity - which refers to decisionmaking capability. The Convention does not in any way mention 'mental capacity'. ${ }^{103}$

The Assisted Decision-Making (Capacity) Bill was published in July 2013. It presents an interesting mix of supports (including the option of entering binding assisted decisionmaking agreements ${ }^{104}$ and co-decision-making agreements ${ }^{105}$ and substitute decisionmaking (such as decision-making representatives ${ }^{106}$ and informal decision-makers), ${ }^{107}$ but continues to be premised on the individual reaching a certain standard of mental capacity as a prerequisite for retaining legal capacity in respect of a given decision. The definition of capacity does not include a diagnostic step (i.e. impairment in the functioning of the mind or brain) which, on one view, makes it less obviously discriminatory, but on the other hand, any of the forms of decision-making prescribed under the Bill may only occur where the

99 Amnesty Ireland and Centre for Disability Law and Policy, Essential Principles for Legal Capacity Reform (2012) $<$ htwww.nuigalway.ie/cdlp/documents/principles_web.pdf > accessed 26 April 2013.

100 Oireachtas, 'Committee on Justice, Defence and Equality Continues Hearings on Proposed Mental Capacity Legislation' press release (February 2012) <www.oireachtas.ie/parliament/mediazone/pressreleases/ 2012/name-6931-en.html> accessed 26 April 2013.

101 Oireachtas Joint Committee on Justice, Defence and Equality, Report on Hearings in Relation to the Scheme of the Mental Capacity Bill (May 2012) <www.oireachtas.ie/parliament/media/michelle/Mental-capacity-textREPORT-300412.pdf> accessed 28 May 2013.

102 Ibid 7.

103 Ibid 8.

104 Assisted Decision-Making (Capacity) Bill 2013, s 10.

105 Ibid s 18.

106 Ibid s 24.

107 Ibid s 53. 
individual considers that her capacity is either 'in question' or 'shortly may be in question'108 which seems to imply that the main group of individuals affected by the legislation will be those with impaired decision-making ability - especially persons with cognitive disabilities.

A detailed discussion of the legislation is outside the scope of this paper, but it is important to note that, even in the substitute decision-making provisions of the Bill, intervenors are obliged to act in conformity with the guiding principles of the Bill, which include respect for the will and preferences of the individual (albeit with the qualifier that this should only be done 'as far as practicable'). ${ }^{109}$ It is also significant that best interests does not appear as a principle for guiding decision-making under the Bill.

The definition of capacity set out in s 3 of the Bill reveals that the underlying premise of the legislation is that a certain standard of mental capacity is a prerequisite for the recognition of an individual's legal capacity - a premise which is not, in my view, compatible with the Committee on the Rights of Persons with Disabilities' interpretation of Article 12. Nevertheless, despite this view, legal recognition of various supports necessary to exercise legal capacity (such as assisted decision-making and co-decision-making) are provided in the Bill, which is certainly to be welcomed.

At a minimum, there has been more awareness-raising and recognition in the Republic (than in Northern Ireland) of the need for legislation on capacity to abolish substitute decision-making in order to comply with the provisions of Article 12. In light of the commitment in the Belfast/Good Friday Agreement to ensure equivalence of protection for human rights on both sides of the border, ${ }^{110}$ therefore, I suggest that the more progressive approach which appears to be the focus of new legislation in the Republic should be reflected in the development of legislation on capacity in Northern Ireland.

\section{Conclusion}

Since the entry into force of the CRPD, many countries are struggling to come to terms with the reforms necessary - and Article 12 on legal capacity is one of the most complex areas of law in need of reform. Members of the UN Committee on the Rights of Persons with Disabilities have repeatedly stated that no country is currently fully in compliance with Article 12, since the full replacement of substituted decision-making with supported decision-making has not yet been achieved. ${ }^{111}$ Nevertheless, the Committee continues to require States Parties to take steps to eliminate regimes of substitute decision-making and replace these with supports to exercise legal capacity. Some important reform processes are currently underway throughout the world, including in the Republic of Ireland, as discussed above, and also in India ${ }^{112}$ and the Canadian province of Newfoundland and Labrador. ${ }^{113}$

108 Assisted Decision-Making (Capacity) Bill 2013, s 2 (see definition of 'relevant person').

109 Ibid s 8 .

110 See Cinnéide (n 5).

111 See, for example, T Degener, 'Monitoring the UN Convention on the Rights of Persons with Disabilities' (keynote address at Getting Ready to Ratify: The UN Convention on the Rights of Persons with Disabilities, Dublin, 17 May 2013).

112 See Committee appointed by Ministry of Social Justice and Empowerment, Government of India, The Rights of Persons with Disabilities Bill 2011 (Centre for Disability Studies, NALSAR University of Law, Hyderabad 2011) < http://socialjustice.nic.in/pdf/report-pwd.pdf> and Draft National Trust Act Amendments 2011 <http://thenationaltrust.co.in/nt/images/national\%20trust\%20amendment.pdf > accessed 28 May 2013.

113 See Newfoundland and Labrador Association of Community Living, Policy Document Submitted to Justice Aims to Aid People with Intellectual Disabilities <www.nlacl.ca/news/article/getting-power-make-decisions-policydocument-submi/> accessed 26 April 2013. 
It is therefore surprising that the requirements of Article 12 have had so little influence on the development of the Mental Capacity (Health, Welfare and Finance) Bill in Northern Ireland. With the exception of Mencap and some isolated disability organisations, there has been relatively little campaigning from civil society on the need for the new legislation to move away from substitute decision-making in order to comply with the CRPD. Similarly, the independent mechanism which oversees domestic implementation of the CRPD, appears to have only published one set of comments on the legislation which refer to the need for it to be CRPD-compliant - but does not challenge the central premise of the legislation, which is based on a functional assessment of mental capacity and the subsequent removal of legal capacity for a particular decision. While legislation in the Republic may not ultimately comply with all the requirements of Article 12 - at least there has been open acknowledgment from government on the need for the legislation to enable ratification of the CRPD 114 and repeated calls from civil society to place supported decision-making at the heart of the new Bill. ${ }^{115}$

In this paper I have sought to draw out the discontinuities between the legislative proposals in Northern Ireland, the requirements of Article 12 CRPD and the attempts to legislate for supported decision-making in the Republic of Ireland. The arguments presented will, I hope, serve to open further cross-border collaboration and discussion at both government and civil society levels on the need to uphold the fundamental rights of persons with disabilities - especially the right to legal capacity - one of the core human rights necessary for the enjoyment and exercise of almost all other rights.

114 Dail Debates (n 96).

115 Amnesty Ireland and Centre for Disability Law and Policy, Essential Principles for Legal Capacity Reform (2012) <www.nuigalway.ie/cdlp/documents/principles_web.pdf> accessed 26 April 2013. 
